DOI: $10.31249 / \mathrm{rsm} / 2019.03 .14$

\title{
С.И. Коданева
}

\section{ИНСТИТУЦИОНААИЗАЦИЯ СОЦИАЛЬНОЙ ОТВЕТСТВЕННОСТИ ГОСУААРСТВА В РОССИИ И ЗА РУБЕЖОМ}

Аннотация. Статья посвящена актуальной проблеме - формированию и проведению сочииально-ответственной политики в Российской Федераџии. Проанализирована российская литература, отражающая становление понятия социальной ответственности, подходы отечественных ученых $\kappa$ пониманию ее сущности $и$ различных форм. Показано, что современные авторы выделяют различные аспекты социальной ответственности государства, не рассматривая ее комплексно, как это требует утвержденная ООН Повестка дня в области устойчивого развития на период до 2030 г. Анализируется зарубежная литература по различным аспектам социиальной ответственности государства (экономическому, социальному и экологическому), а также их отражение в конституционном праве некоторых стран Европы, в Соединенных Штатах Америки, Канаде, Китае, ЮАР. Стран, конституционно и законодательно закрепивших сочиальную ответственность государства, не так много, что объясняется широким распространением традиций неолиберализма. Так, например, США и Канада практически не уделяют внимания вопросам социальной ответственности государства, используя их исключительно как политический инструмент.

Предложен комплексньй подход, предполагающий, что сочиальная ответственность государства не сводится лишь к социальной или экологической составляющей: только сбалансированное развитие всех трех компонентов - социального, экологического и экономического - позволяет обеспечить устойчивое развитие государства.

Этот комплексный подход применяется к социальной ответственности Российского государства. Автор, проанализировав Конституцию и законодательство Российской Федерации, рассмотрев основные документы стратегического планирования, обосновывает, что отсутствие конституционного и законодательного закрепления сочиальной ответственности государства в РФ приводит и к отсутствию комплексной сочиально-ответственной политики. Соответственно, мероприятия, направленные на решение экономических, экологических и сочиальных проблем, носят разрозненный характер. Кроме того, это препятствует осуществлению на практике важнейших инищиатив в области экологии. Такое отсутствие комплексности приводит к дисбалансу в развитии трех указанных выше компонентов. Это в конечном итоге не позволяет обеспечить устойчивое развитие странь в иелом. 
Ключевые слова: социальная ответственность государства; сочиальное и экономическое развитие; Российская Федераџия; Конституцฺи России.

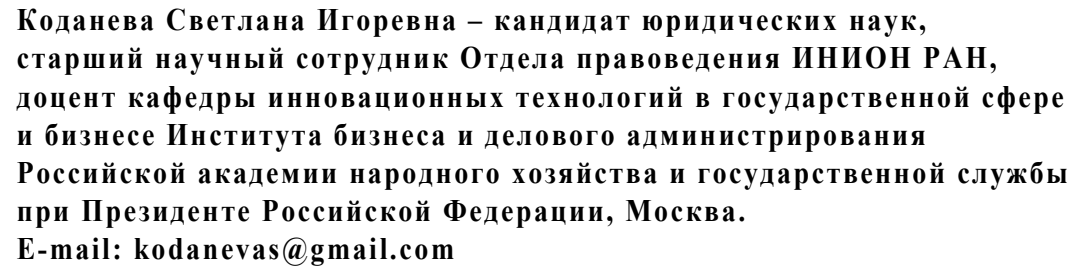

\section{S.I. Kodaneva. Institutionalization of Social Responsibility of the State in Russia and Abroad}

Abstract. The article is devoted to the actual problem of formation and implementation of socially responsible policy in the Russian Federation. The analysis of the Russian literature, reflecting both the history of the concept of social responsibility and the approaches of domestic scientists to understanding the essence of social responsibility of the state and its various forms of manifestation. It is revealed that modern authors in their studies reflect various aspects of social responsibility of the state, not considering it comprehensively as demanded by the United Nations in the approved 2030 Agenda for sustainable development. The author analyzes foreign literature on various aspects of social responsibility of the state (economic, social and environmental), as well as their reflection in the constitutional law of the European countries, the United States of America, Canada, China and developing countries in Africa. Few countries have constitutionally and legislatively established the social responsibility of the state, which is explained by the widespread traditions of neoliberalism in the world. For example, the United States and Canada pay little attention to the social responsibility of the state, using it exclusively as a political tool.

The novelty of this study lies in the proposed integrated approach, in which the social responsibility of the state should not be reduced to the social or environmental component, since only the balanced development of all three components, social, environmental and economic, will ensure the sustainable development of the state. According to the results of the study, approaches to extrapolation of such an integrated approach to the scope and forms of manifestation of social responsibility of the Russian state are proposed. The author, having analyzed the Constitution and legislation of the Russian Federation, having considered the main documents of strategic planning, comes to the conclusion that the lack of constitutional and legislative expression of social responsibility of the state in the Russian Federation leads to the absence of a comprehensive socially responsible policy. Accordingly, activities aimed at solving economic, environmental and social problems are fragmented. In addition, it prevents the implementation of major initiatives in the field of ecology. This lack of complexity leads to an imbalance between the objectives of these three components. This ultimately does not allow for the sustainable development of the country as a whole.

Keywords: social responsibility of the state; social and economic development; Russian Federation; the Constitution of Russia. 


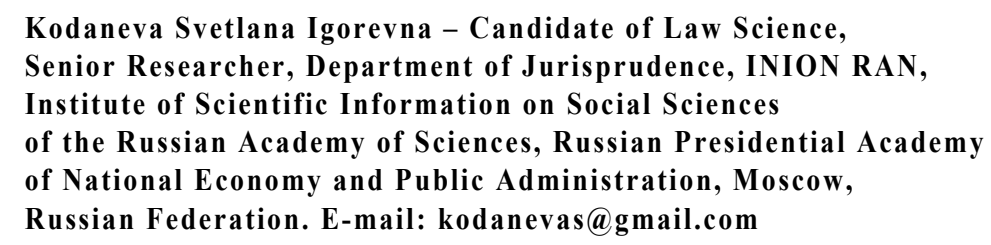

За последние несколько лет появилось немало научной литературы по тематике сначала устойчивого развития, а позже - корпоративной социальной ответственности. Это обусловлено активной позицией многих неправительственных и международных организаций, прежде всего ЮНЕСКО и ООН. Последняя подготовила два важных документа. В 1987 г. был опубликован доклад «Наше будущее», а в 2015 г. - принята резолюция «Преобразование нашего мира: Повестка дня в области устойчивого развития на период до 2030 года».

Само понятие социальной ответственности появилось в начале XX в., а первое серьезное исследование на эту тему было написано Хоурдом Боуэном в 1950-х годах. Именно в тот период началось переосмысление места и роли бизнеса в обществе. И несмотря на различие подходов к определению «корпоративной социальной ответственности» (так, А. Кэрролл в своей статье, опубликованной в 1999 г., рассмотрел около 30 ее определений в академической литературе) [Carroll 1999], общим является понимание социальной ответственности как обязательства бизнеса приносить пользу обществу через использование получаемых им прибылей.

В общем виде в развитии понятия «корпоративная социальная ответственность» можно выделить четыре этапа, четыре основные подхода к пониманию ее сути.

Первый этап - зарождение понятия, когда под социальной ответственностью понималось успешное развитие бизнеса. Так, известный экономист М. Фридман отмечал, что бизнес должен служить только интересам своих собственников. Главная его задача - представлять обществу товары и услуги по разумным ценам, и именно в этих ценах и будет проявляться социальная ответственность бизнеса перед обществом. Кроме того, успешный бизнес это стабильные налоги, которые должны позволить государству заниматься социальными проблемами [Friedman 1970].

Второй этап трансформации понятия «социальная ответственность» связан с «Великой депрессией» и усилением роли профсоюзов. На этой стадии она стала подразумевать ответственность бизнеса перед своими работниками. Таким образом, сформировалось то, что мы сегодня называем «внутренней социальной ответственностью» или «корпоративным гражданством». Кроме того, появляется понятие «социальной ответственности заинтересованных 
лиц〉 - обязанность бизнеса вести честную конкуренцию и раскрывать часть информации для заинтересованных лиц (клиентов, государства и т.д.).

Третий этап начинается с 1960-х годов, когда на Западе социальная ответственность становится неотъемлемой частью функционирования бизнеса и начинает восприниматься как его вовлеченность в социальную жизнь общества, в частности посредством благотворительности, поддержки наиболее социально уязвимых групп населения.

Наконец, сегодня мы переходим к четвертому этапу, когда понятие «социальной ответственности» существенно расширяется, выходя на международный уровень, где говорится уже не просто об устойчивом экономическом развитии отдельных компаний или устойчивом экологическом развитии региона, а об устойчивом развитии всей планеты.

Так, в 2015 г. была принята упомянутая выше Резолюция ООН, в которой сформулированы 17 целей устойчивого развития и указано, что их реализация предполагает активное всеобщее участие, вовлечение всех имеющихся ресурсов, включая правительства, частный сектор, гражданское общество, систему ООН и других субъектов.

Таким образом, подход, сформулированный ООН, предполагает, что в современных условиях социальная ответственность значительно шире, чем просто ответственность бизнеса за своих работников или благотворительность.

Речь уже идет об активном взаимодействии частного сектора и государства в решении множества сложнейших проблем как в области экологии и социального обеспечения нуждающихся, так и в обеспечении устойчивого экономического развития. Таким образом, социально-ответственное поведение сегодня должен демонстрировать не только бизнес, но прежде всего государство. А следовательно, возникает вопрос, как должна быть институционализирована социальная ответственность государства, в каких формах она должна реализовываться и вообще - что следует понимать под социальноответственным государственным управлением?

Обратимся к анализу научной литературы по проблеме социальной ответственности государства (власти) и опыту институционализации (конституционализации) социальной ответственности в зарубежных странах.

Публикаций по данной тематике в российских изданиях крайне мало. Их анализ показывает, что авторы, как правило, делятся на два лагеря.

Большинство из них сводит социальную ответственность государства исключительно к социальной или социально-экономической политике государства.

Так, Ю.А. Чистобаева видит социальную ответственность государства в повышении благосостояния населения посредством государственных социальных стандартов, отмены подоходного налога с минимальной заработной 
платы и создания многоуровневой системы социальной защиты [Чистобаева 2012].

Е.Н. Васин определяет главное назначение и сущностную характеристику государственной социальной ответственности как обеспечение социальной свободы, независимости и возможности реализации человеческой индивидуальности. В его понимании социальная ответственность включает помимо социальной политики также обеспечение прав меньшинств и политкорректность [Васин 2011].

В.П. Бардовский предлагает использовать социальную ответственность как метод регулирования социально-трудовых отношений посредством социального партнерства органов власти, работодателей и профсоюзов [Бардовский 2015].

Вторая группа авторов придерживается классического понимания социальной ответственности как ответственности бизнеса. Социальную же ответственность государства они видят в создании стимулов для социально ответственного поведения бизнеса.

Например, Н.В. Кузнецова подчеркивает, что в России отсутствует механизм формирования социальной ответственности как системы. Поэтому, по мнению автора, важной сферой социальной ответственности государства должно стать его «участие в принятии решений, связывающих проведение экономической политики с урегулированием социальных задач». Прежде всего это касается реализации крупных инвестиционных проектов [Кузнецова 2012].

Е.В. Нехода также полагает, что социальная ответственность власти заключается в том, что «государство своими действиями должно способствовать реализации социальных программ на предприятиях начиная с формирования общественного мнения и проведения разного рода конкурсов с обнародованием результатов до возможного выпуска специализированных статистических сборников» [Нехода 2003].

По мнению В.М. Ишимова и В.М. Капицына, государство должно содействовать развитию крупного частного капитала, тем самым стимулируя его к проведению социально-ответственной политики. Для этого государство может использовать такие инструменты, как госзаказы, субсидирование процентных ставок, реструктуризация налоговой задолженности, софинансирование инвестиционных проектов, кредитование под государственные гарантии и т.п. [Ишимов, Капицын 2012].

Анализ зарубежной литературы также позволяет выделить два подхода государства к вопросам социальной ответственности, однако эти подходы несколько отличаются от изложенных выше. В первом случае национальные правительства принимают часть социальной ответственности на себя, либо активно участвуют в развитии практики корпоративной социальной ответст- 
венности бизнеса (далее - КСО). Это может быть обусловлено тремя разными причинами: 1) КСО является способом узаконить политику государства; 2) государство разделяет с бизнесом бремя социальной защиты, предоставляя минимальный социальный набор своим гражданам; наконец, 3) государство таким образом перекладывает свои социальные функции на бизнес и общество. Второй подход связан с косвенным стимулированием государством развития КСО посредством правовых, экономических, информационных, гибридных и партнерских механизмов [Idemudia, Kwakyewah 2018, с. 929].

Таким образом, практика институционализации социальной ответственности в различных государствах крайне неоднородна. Прежде всего это обусловлено исторически сложившимися экономическими и политическими системами государств. Там, где преобладает либеральный подход, государство, как правило, не принимает на себя бремя социальной ответственности перед своим населением, полностью перекладывая его на общество и бизнес.

Так, в США традиционно многие социальные вопросы, такие как образование, здравоохранение или экология, входили в зону ответственности самого общества, поэтому никакие обязанности государства в этих сферах никогда не были закреплены не только в конституции страны, но даже в ее законодательстве. Поэтому в США сформировался феномен «корпоративного гражданства» - социально-ответственного поведения компаний, прежде всего крупных корпораций. Он зиждется на понимании того, что хорошая репутация - это основа долгого существования. Действительно американские компании жертвуют на благотворительные цели в 10 раз больше своих британских коллег, но в то же время они потребляют существенно больше, чем позволяет экологический потенциал страны, а средней американской гражданин использует в 11 раз больше ресурсов, чем средний китаец, и в 32 раза больше, чем средний кениец [Camilleri 2017]. Дело в том, что в США вопросы обеспечения устойчивого развития страны и социальная ответственность правительства не закреплены конституционно, поэтому нет и их жесткой законодательной регламентации.

Тем не менее федеральное правительство Америки принимает самое активное участие в реализации требований социальной ответственности по всему миру. Главную роль в этом играет госсекретарь США, а также ряд федеральных органов и созданных ими фондов. Например, это Бюро по вопросам экономики и бизнеса. Его основная цель заключается в поощрении ответственной деловой практики и содействии устойчивому развитию при одновременном укреплении экономической безопасности. Бюро по вопросам демократии, правам человека и труду, а также созданный им Фонд по правам человека и демократии заботятся о том, чтобы в производственно-сбытовых цепочках не использовался рабский труд. В частности, от американских компаний с оборотом более 100 млн долл. требуется ежегодно публиковать 
нефинансовые отчеты, в которых, в числе прочего, должно быть указано, как они проверяют свои цепочки поставок.

Причем аналогичные программы реализуются и за пределами США (в основном благодаря крупным транснациональным корпорациям), что «призвано минимизировать нарушения прав человека, поддерживать демократических активистов во всем мире, открывать политическое пространство в зарождающихся демократиях и авторитарных режимах, а также вносить позитивные транснациональные изменения в общество» [Camilleri 2017, c. 12].

Что же касается вопросов экологии, то Соединенные Штаты отстают от других стран, особенно в областях, связанных с устойчивыми энергетическими инфраструктурами, негативными последствиями загрязнения воздуха и воды. Это вызвано отсутствием законодательного регулирования в данной сфере и минимальной КСО, а также отказом страны от участия в международных договорах.

В соседней с США Канаде также преобладает неолиберальный подход к роли государства, основанный на признании главенствующей роли рынка и его саморегулирования. Однако поскольку крупные добывающие корпорации Канады осуществляют свою деятельность на территории развивающихся стран, нанося им зачастую непоправимый экологический и социальный вред, включая случаи прямого нарушения прав человека, это подрывает «социальную лицензию» на их деятельность, что может нанести Канаде внешнеполитический и экономический урон. Это заставило правительство обратиться к регулированию вопросов КСО.

Следует отметить, что ни в политической риторике, ни в законодательстве Канады термин «социальная ответственность» не используется применительно к внутренней политике или обязательствам государства по отношению к своему собственному населению. Поэтому критики указывают на то, что правительство тратит деньги своих налогоплательщиков на защиту интересов и без того богатых крупных корпораций [Idemudia, Kwakyewah, 2018].

Но даже применительно к деятельности указанных корпораций правительство Канады не отходит от главного принципа - саморегулирования, поэтому был использован механизм «мягкого закона» - утверждение Национальной стратегии в области КСО, носящей рекомендательный характер. В ней указано: «Правительство ожидает, что канадские компании интегрируют КСО во все свои структуры управления, с тем чтобы они работали за рубежом на экономической, социальной и экологически устойчивой основе. Это означает, что компании должны осознавать влияние каждой из своих функций на экономику, сообщество и окружающую среду, а также корректировать свою деятельность и операции, чтобы создать ценность для себя и для других заинтересованных сторон... а также стремиться предотвращать возможные конфликты» [Idemudia, Kwakyewah 2018, с. 932]. При этом 
единственной формой контроля за соблюдением корпорациями принципов социально-ответственного поведения и ответственности корпораций является опубликование информации о том, как они соблюдают (или не соблюдают) требования КСО, с тем чтобы это стало достоянием гражданского общества.

Что касается Европы, то здесь ситуация несколько более разнородна. Например, в соответствии с конституционно закрепленными обязанностями государственные органы Швеции вмешиваются в рыночные отношения различными способами. Во-первых, государство осуществляет нормативное регулирование в целях обеспечения общественных благ, которые рынок сам по себе не стал бы обеспечивать на основе собственной внутренней логики. Вовторых, государство всеобщего благоденствия можно понимать как политический механизм управления рыночными неудачами и рыночными внешними факторами, которые сглаживаются путем предоставления гражданам социальных услуг и социального страхования на нерыночной основе [Lindh 2015].

Соответственно, добровольная КСО здесь не может предложить серьезную полномасштабную альтернативу государству всеобщего благоденствия: шведы по-прежнему считают государственные органы конечным институциональным гарантом социального обеспечения, в то время как широкое внедрение КСО может привести к тому, что важные вопросы социальной политики уйдут из сферы ответственности государства и, что важно, демократического контроля.

Следует отметить, что лишь немногие государства прямо законодательно или конституционно закрепляют принципы социальной ответственности. Интересно, что ярким примером противоположного подхода стал Уэльс - автономный регион Великобритании. Как известно, Великобритания не имеет писаной конституции. Соответственно, конституционный статус составляющих ее регионов закреплен в актах парламента Великобритании, к каковым относится и Акт 2006 г. Однако в его разработке принимали участие представители Уэльса, обладающего довольно широкими правами автономии. Таким образом, закрепление в данном квази-конституционном акте положений об ответственности правительства Уэльса за обеспечение устойчивого развития является волей самого этого региона.

В целях реализации Акта об управлении Уэльсом 2006 г. в 2009 г. был утвержден «План устойчивого развития “Один Уэльс: одна планета"», а в 2015 г. Ассамблея Уэльса приняла Акт о благополучии будущих поколений. В этих документах устойчивое развитие признается основополагающим организационным принципом деятельности правительства Уэльса. В этом заключается «ключевая особенность Уэльса в процессе передачи ему полномочий автономии» [Pigott 2018, с. 3].

Указанные документы написаны в терминологии и стиле документов Организации Объединенных Наций, посвященных целям устойчивого развития 
человечества. Так, провозглашается, что Уэльс живет в пределах своих экологических возможностей, ограничивая использование ресурсов земли и сохраняя устойчивость к воздействиям изменения климата; имеет здоровые, биологически разнообразные и продуктивные экосистемы; надежную и устойчивую экономику, которая может развиваться при стабилизации, а затем сокращении использования природных ресурсов; имеет общины, которые являются безопасными, устойчивыми и привлекательными местами для жизни и работы людей, где люди обеспечены необходимыми услугами и хорошей системой здравоохранения; является справедливой и двуязычной нацией, в которой граждане всех возрастов и происхождения имеют право определять свою собственную жизнь, формировать свои общины и полностью реализовывать свой потенциал.

Если сравнивать эти положения с целями устойчивого развития, сформулированными ООН, то сходство становится очевидным.

В Акте 2015 г. на все государственные органы Уэльса возложена обязанность действовать в соответствии с этими целями, а также постоянно проводить общенациональные консультации с населением региона в рамках проекта «Уэльс, который мы хотим». По мнению правительства Уэльса, это должно заставить государственные органы больше думать о долгосрочной перспективе, лучше работать с населением региона и различными общинами, а также эффективнее взаимодействовать друг с другом.

Другим примером страны, конституция и законодательство которой основаны на документах $\mathrm{OOH}$ в области социальной ответственности и устойчивого развития, является Южно-Африканская Республика.

Поскольку политика апартеида была прекращена в 1990-х годах, когда ООН уже достаточно остро поднимала проблему устойчивого развития, то ЮАР практически сразу восприняла документы ООН в качестве руководящих принципов для себя, что нашло отражение и в конституции страны. ЮАР является одной из немногих стран мира, где речь идет именно о комплексном понимании устойчивого развития, включающем все три компонента: социальный, экологический и экономический (как правило, акцент смещается в какую-то одну из указанных трех сфер).

Итак, в Конституции и законодательстве ЮАР, основанных на положениях Доклада ООН 1987 г. «Наше будущее», было закреплено, что устойчивое развитие обеспечивает интеграцию экономической системы, социальнополитической системы и экосистемы через систему управления, с тем чтобы они оставались взаимосовместимыми по мере решения ключевых задач в области развития, связанных с искоренением нищеты и серьезным неравенством. Важнейшее значение в этом определении имеет удовлетворение потребностей бедных слоев населения и недопущение истощения ресурсов в целях удовлетворения потребностей будущих поколений [Kalumba и др. 2016, с. 2]. 
В соответствии с Конституцией ЮАР устойчивое развитие является общей ответственностью различных уровней управления, но как в сфере промышленности, так и в экологической области в наибольшей степени они отнесены к компетенции местного самоуправления. Поэтому в литературе по социальной ответственности корпораций, действующих на территории Африки, как правило, говорится об «устойчивых общинах».

Наконец, обзор литературы по конституционному регулированию вопросов социальной ответственности был бы неполным без примера Китая, поскольку эта страна стала центром внимания для всего мира из-за огромного роста ВВП и производственных мощностей за последние два десятилетия. Такие темпы экономического роста и процветания привели к возникновению множества экологических проблем по всей стране.

При этом как государство, так и отдельные компании до недавнего времени были заинтересованы только в одном - максимальном экономическом росте и получении максимально возможной прибыли. Осознание экологических проблем, к которым это привело, заставило правительство Китая обратить внимание на необходимость внедрения КСО в китайских компаниях. В связи с этим на государственном уровне был заявлен лозунг о создании «гармоничного общества» и решимости обеспечить «сбалансированный и устойчивый рост» [Shahab, Chengang 2018, с. 92].

Во второй половине 2000-х годов китайским правительством, регулирующими органами и неправительственными организациями были приняты некоторые инициативы и рекомендации, направленные на создание стимулов для преодоления экологических проблем, расширения практики КСО, включая обязательное или добровольное раскрытие нефинансовой информации китайскими предприятиями. При этом конституционного отражения и закрепления такие инициативы не нашли. В результате, как показывают эмпирические исследования, высокий процент государственной собственности в китайских фирмах приводит к низкому уровню КСО. Это означает, что само государство препятствует КСО и раскрытию информации [Shahab, Chengang 2018, c. 100].

Таким образом, анализ российской и зарубежной литературы позволяет сделать вывод, что содержание социальной ответственности государства является таким же сложным и многогранным, как и сама природа институтов власти.

Однако даже в рамках неолиберального подхода государство активно участвует в формировании социально-ответственного бизнеса (либо через свои органы, либо посредством утверждения программных документов). В то же время представляется, что для России такие механизмы вряд ли могут быть достаточно эффективными в силу исторически сложившейся системы взаимодействия государства, общества и бизнеса, где роль государства сильно 
гипертрофирована, а органы власти могут выступать в разных ролях в зависимости от конкретной сферы их действий.

Так, по своей природе органы власти созданы для выполнения властных функций, формирования и претворения в жизнь политики государства. $\mathrm{C}$ другой стороны, сегодня все чаще органы власти позиционируют себя как поставщики социальных услуг обществу и гражданам. В гражданском правообороте государство выступает наравне с другими субъектами - юридическими и физическими лицами. Наконец, государство оказывает меры поддержки различным категориям бизнеса, тем самым стимулируя его к развитию и в конечном итоге достижению общественно значимых целей.

Таким образом, невозможно свести социальную ответственность государства только к какой-то одной ее форме, ограничивая его роль только социальной политикой по поддержке незащищенных слоев населения, решением экологических проблем или стимулированием бизнеса к социальноответственному поведению.

В отношении внутренних форм корпоративной социальной ответственности, таких как безопасность труда, дополнительное медицинское страхование работников, развитие кадрового потенциала организаций, обеспечение стабильности работы и зарплаты и т.д., безусловно, государство должно выступать с позиции власти, стимулируя бизнес к подобного рода социальной ответственности, а при необходимости - контролируя и обязывая его к социально ответственному поведению в отношениях со своими работниками [Коданева 2018].

Что же касается так называемых внешних форм социальной ответственности, то здесь можно взять за образец опыт ЮАР, где реализован наиболее комплексный подход, предпринята попытка увязать вместе социальноэкономическое и экологическое устойчивое развитие государства.

Очевидно, что государство, выступая в роли субъекта социальной ответственности, предстает в различных ипостасях. Для примера возьмем проблему утилизации и захоронения отходов, в рамках решения которой можно говорить как о социальной ответственности бизнеса (и предприятий, производящих отходы, и тех, в чьей собственности находятся объекты захоронения и утилизации отходов), так и государства. Причем государство несет ответственность за обеспечение благоприятной экологической ситуации в соответствии с Конституцией Российской Федерации, а органы власти обязаны обеспечивать надзор за соблюдением экологических требований всеми участниками процесса сбора, хранения и утилизации отходов.

И в то же время государство должно создавать стимулы для социальноответственного бизнеса как в части снижения объемов производимых отходов, так и в части реализации проектов строительства мусороперерабаты- 
вающих заводов. Это могут быть как прямое софинансирование, так и система налоговых и иных льгот.

Однако реализация такого комплексного подхода возможна только в рамках продуманной государственной политики, основанной на официальном признании государством своей социальной ответственности по обеспечению устойчивого развития страны и выработке соответствующих программных документов.

Между тем в основополагающем документе стратегического планирования - Послании Президента Федеральному Собранию 2018 г. - говорится только о достигнутой устойчивости национальной экономики. Тема устойчивого развития поднимается только один раз - в разделе, посвященном международным отношениям в контексте международной безопасности [Послание 2018]. Хотя нельзя не признать, что многие положения Послания полностью соответствуют целям устойчивого развития, сформулированным $\mathrm{OOH}$, тем не менее в нем отсутствует комплексность, о которой мы говорили выше.

Следующим важным документом стратегического планирования в соответствии с Федеральным законом от 28.06.14 № 172-Ф3 «О стратегическом планировании в Российской Федерации» должна быть Стратегия социальноэкономического развития Российской Федерации, в которой определялись бы цели, основные приоритеты и задачи социально-экономического развития на долгосрочный период. Соответственно, именно Стратегия могла бы стать программным документом, базирующимся на принципах социальной ответственности государства за устойчивое развитие России. Однако данный документ до настоящего времени не разработан.

Не находит отражения комплексный социально-ответственный подход к развитию России и в Основных направлениях деятельности Правительства Российской Федерации на период до 2024 г. (утвержден Правительством РФ 29.09.2018).

Все сказанное выше позволяет сделать вывод, что в российской политике не нашли понимания и поддержки идеи, закрепленные в Докладе ООН 1987 г. и Резолюции ООН 2015 г. Отчасти это объясняется отсутствием прямого конституционного закрепления ответственности органов власти РФ за обеспечение устойчивого развития государства.

Безусловно, ст. 7 Конституции декларирует, что Российская Федерация социальное государство, политика которого направлена на создание условий, обеспечивающих достойную жизнь и свободное развитие человека; кроме того, ст. 39, 41-43 закрепляют права граждан на социальное обеспечение, охрану здоровья, образование и благоприятную окружающую среду [Конституция]. То есть конституция закрепляет минимальные социальные гарантии для своих граждан. 
Однако толкование объема таких гарантий целиком отнесено к полномочиям органов власти. В частности, разработку основополагающих стратегических документов, на основании которых должны формироваться как приоритеты развития страны (включая приоритеты социальной, экологической и экономической политики), так и необходимое для этого законодательство, осуществляют органы исполнительной власти, прежде всего Министерство экономического развития РФ. Фактически именно к их компетенции относится вопрос определения объема социальной ответственности Российского государства перед своими гражданами.

Это препятствует гармонизации экономики, экологии и социального развития страны, противореча ключевым целям, обозначенным ООН. В результате не реализуются важные социальные и экологические проекты, в частности направленные на снижение объема сжигания попутного газа в нефтедобыче или внедрение современных методов сортировки и утилизации отходов.

Поэтому очень важно закрепить именно на законодательном уровне и в документах стратегического планирования основные принципы и приоритеты комплексной социально-ответственной политики государства, обязательных для всей системы органов власти Российской Федерации. Это позволит сделать шаг к институционализации как социальной ответственности бизнеса, так и государства в целом.

\section{Библиография}

Бардовский В.П. Формирование социальной ответственности государства, бизнеса и профсоюзов // Экономическая среда. 2015. № 12. С. 63-67.

Васин Е.Н. Генезис государственной социальной ответственности в Европейских государствах // Теория и практика общественного развития. 2011. № 6. С. 56-60.

Ишимов В.М., Капицын В.М. Монопрофильные города: устойчивое развитие и социальная ответственность // Местное самоуправление и развитие территорий. 2012. № 1. С. 64-74.

Коданева С.И. Проблемы идентификации социальной ответственности современного Российского государства // Тренды и управление. 2018. № 3. С. 83-92.

Конституция Российской Федерации // Президент России: Официальный сайт. URL: http://kremlin.ru/acts/constitution (Дата обращения 15.03.2019.)

Кузнецова Н.В. О реализации социальной ответственности на региональном уровне в России // Вестник ТГЭУ. 2012. № 1. С. 40-47.

Нехода Е.В. Социальная ответственность бизнеса и управления: сущность и основные направления реализации // Вестник Томского государственного университета. 2003. № 279. C. $186-190$.

Послание Президента Российской Федерации В.В. Путина Федеральному Собранию Российской Федерации 01.03.2018 г. // Президент Российской Федерации: Официальный сайт [Электронный pecypc]. URL: http://kremlin.ru/events/president/news/56957 (Дата обращения: 01.12.18.)

Чистобаева Ю.А. Институционализация социальной ответственности государства как фактор повышения уровня социализации Российской экономики // Социально-экономические явления и процессы. 2012. № 7-8. С. 187-191. 
Camilleri M. Corporate citizenship and social responsibility policies in the United States of America // Sustainability Accounting, Management and Policy Journal. 2017. Vol. 8. P. 1-35. URL: http://dx.doi.org/10.1108/SAMPJ-05-2016-0023 (Дата обращения: 01.12.18.)

Carroll A.B. Corporate Social Responsibility: Evolution of Definitial Construct // Business \& Society. 1999. Vol. 38. No 3. P. 268-295.

Friedman M. The social responsibility of business is to increase its profit // The New York Times Magazine. 1970. No 3.

Idemudia U., Kwakyewah C. Analysis of the Canadian national corporate social responsibility strategy: Insights and implications // Corporate Social Responsibility and Environmental Management. 2018. Vol. 25. P. 928-938.

Kalumba A.M., Olwoch J.M., Aardt I. Van, Botai J.O., Rautenbach C.J. Industrial development zone and South African environmental legal initiatives post-1994: a quest for sustainable industrial development // Journal of Environmental Planning and Management. 2016. P. 1-21. URL: http://dx.doi.org/10.1080/09640568.2016.1160828 (Дата обращения: 01.12.18.)

Lindh A. Public support for corporate social responsibility in the welfare state: evidence from Sweden // Scandinavian Political Studies. 2015. Vol. 38. No 1. P. 75-94.

Pigott A. Imagining socioecological transformation: an analysis of the Welsh Government's policy innovations and orientations to the future // Elementa Science of the Anthropocene. 2018. Vol. 6. Art. 60. P. 1-18. URL: https://doi.org/10.1525/elementa.315 (Дата обращения: 01.12.18.)

Shahab Ya., Chengang Ye. Corporate social responsibility disclosure and corporate governance: empirical insights on neo-institutional framework from China // International Journal of Disclosure and Governance. 2018. Vol. 15. No 2. P. 87-103.

\section{References}

Bardovskij V.P. Formirovanie social'noj otvetstvennosti gosudarstva, biznesa i profsojuzov. Jekonomicheskaja sreda. 2015. No 12. P. 63-67.

Vasin E.N. Genezis gosudarstvennoj social'noj otvetstvennosti v Evropejskih gosudarstvah. Teorija i praktika obshhestvennogo razvitija. 2011. No 6. P. 56-60.

Ishimov V.M., Kapicyn V.M. Monoprofil'nye goroda: ustojchivoe razvitie i social'naja otvetstvennost'. Mestnoe samoupravlenie i razvitie territorij. 2012. No 1. P. 64-74.

Kodaneva S.I. Problemy identifikacii social'noj otvetstvennosti sovremennogo Rossijskogo gosudarstva. Trendy i upravlenie. 2018. No 3. P. 83-92.

Konstitucija Rossijskoj Federacii. Prezident Rossii: Official Website. URL: http://kremlin.ru/ acts/constitution (Date of access: 15.03.2019.)

Kuznecova N.V. O realizacii social'noj otvetstvennosti na regional'nom urovne v Rossii. Vestnik TGJeU. 2012. No 1. P. 40-47.

Nehoda E.V. Social'naja otvetstvennost' biznesa i upravlenija: sushhnost' i osnovnye napravlenija realizacii. Vestnik Tomskogo gosudarstvennogo universiteta. 2003. No 279. P. 186-190.

Poslanie Prezidenta Rossijskoj Federacii V.V. Putina Federal'nomu Sobraniju Rossijskoj Federacii 01.03.2018 g. Prezident Rossijskoj Federacii: Official Website. URL: http://kremlin.ru/ events/president/news/56957 (Date of access: 01.12.18.)

Chistobaeva Ju.A. Institucionalizacija social'noj otvetstvennosti gosudarstva kak faktor povyshenija urovnja socializacii Rossijskoj jekonomiki. Social'no-jekonomicheskie javlenija i processy. 2012. No 7-8. P. 187-191.

Camilleri M. Corporate citizenship and social responsibility policies in the United States of America. Sustainability Accounting, Management and Policy Journal. 2017. Vol. 8. P. 1-35. URL: http://dx.doi.org/10.1108/SAMPJ-05-2016-0023 (Date of access: 01.12.18.) 


\section{ОБЗОРЫ. РЕФЕРАТЫ. РЕЦЕНЗИИ}

Carroll A.B. Corporate Social Responsibility: Evolution of Definitial Construct. Business \& Society. 1999. Vol. 38. No 3. P. 268-295.

Friedman M. The social responsibility of business is to increase its profit. The New York Times Magazine. 1970. No 3.

Idemudia U., Kwakyewah C. Analysis of the Canadian national corporate social responsibility strategy: Insights and implications. Corporate Social Responsibility and Environmental Management. 2018. Vol. 25. P. 928-938.

Kalumba A.M., Olwoch J.M., Aardt I. Van, Botai J.O., Rautenbach C.J. Industrial development zone and South African environmental legal initiatives post-1994: a quest for sustainable industrial development. Journal of Environmental Planning and Management. 2016. P. 1-21. URL: http:// dx.doi.org/10.1080/09640568.2016.1160828 (Date of access: 01.12.18.)

Lindh A. Public support for corporate social responsibility in the welfare state: evidence from Sweden. Scandinavian Political Studies. 2015. Vol. 38. No 1. P. 75-94.

Pigott A. Imagining socioecological transformation: an analysis of the Welsh Government's policy innovations and orientations to the future. Elementa Science of the Anthropocene. 2018. Vol. 6. Art. 60. P. 1-18. URL: https://doi.org/10.1525/elementa.315 (Date of access: 01.12.18.)

Shahab Ya., Chengang Ye. Corporate social responsibility disclosure and corporate governance: empirical insights on neo-institutional framework from China. International Journal of Disclosure and Governance. 2018. Vol. 15. No 2. P. 87-103. 